\title{
El consumo tradicional de los nuevos medios. Análisis de la usabilidad de las publicaciones autóctonas para tableta en el contexto universitario español y brasileño ${ }^{1}$
}

\author{
María Bella Palomo Torres \\ Universidad de Málaga \\ bellapalomo@uma.es \\ Rodrigo E.S. DA CUNHA \\ Universidad Federal de Bahía (Brasil) \\ rodrigoesc@ufba.br
}

Recibido: 6 de marzo de 2015

Aceptado: 25 de septiembre de 2015

\begin{abstract}
Resumen
Esta investigación aborda el consumo que los jóvenes universitarios de España y Brasil realizan de las publicaciones para tabletas. A través del estudio de seis casos -las revistas españolas Don, Vis-à-Vis y Quality Sport, y los vespertinos brasileños O Globo a Mais, de Río de Janeiro; Estadão Noite, de Sao Paulo; y Diário do Nordeste Plus, de Fortaleza- se aplica una metodología cualitativa, el test de usabilidad, para detectar qué aspectos ralentizan y entorpecen la navegación en las nuevas generaciones de usuarios de medios móviles. A pesar de la influencia de las revistas impresas en la configuración de las publicaciones para tableta, los datos muestran que el usuario necesita "entrenarse" para conocer unas opciones de interacción a veces poco intuitivas o para las que carece de la madurez visual necesaria. Por ello las publicaciones más sencillas obtienen los mejores resultados de usabilidad.
\end{abstract}

Palabras clave: tableta, usabilidad, interactividad, dispositivo móvil, diseño.

\section{The traditional use of new media. Usability testing of native tablet publica- tions in the Spanish and Brazilian university context}

\begin{abstract}
This research addresses the consumption of publications for tablets carried out by university students in Spain and Brazil. Through the study of six cases -the Spanish magazine Don, Vis-à-Vis and Quality Sport, and Brazilian evening news Mais O Globo (Rio de Janeiro); Estadão Noite (Sao Paulo); and Diário do Nordeste Plus (Fortaleza)- we applied a qualitative methodology, usability testing, to notice which items slow down and hinder the navigation on the new generation of mobile media device users. Despite the influence of print journals in the configuration of tablet publications, our data show that users need some training for some interaction options sometimes unintuitive or for which there is a visual maturity lack. Therefore the simplest publications perform the best usability results.
\end{abstract}

Keywords: tablet, usability, interactivity, mobile device, design.

\section{Referencia normalizada}

PALOMO TORRES, María Bella y DA CUNHA, Rodrigo E.S. (2016): "El consumo tradicional de los nuevos medios. Análisis de la usabilidad de las publicaciones autóctonas para tableta en el contexto universitario español y brasileño”. Estudios sobre el Mensaje Periodístico. Vol. 22, Núm. 1 (enero-junio), págs.: 483-501. Madrid, Ediciones Complutense.

1 Esta investigación ha sido auspiciada por los proyectos "La influencia de la audiencia en la innovación periodística y Gestión de la participación: riesgos y oportunidades" (CSO201564955-C4-3-R). 
Sumario: 1. Introducción. 2.Publicaciones autóctonos. 3. La usabilidad como método científico. 4. Metodología; 4.1. Selección de los participantes; 4.2. Protocolo; 4.3; Material; 4.4. Selección de las aplicaciones; 4.5. Tareas; 4.6. Cuestionario post-test. 5. Resultados; 5.1. Tareas; 5.2. Publicidad; 5.3. Cuestionario; 5.4. Navegación; 5.5. Botones y gestos; 5.6. Multimedia: vídeos y animaciones; 5.7. Multimedia: galería de imágenes; 5.8. Tutoriales. 6. Conclusiones. 7. Referencias bibliográficas.

\section{Introducción}

E1 90\% de las interacciones en el consumo mediático se producen en pantallas. El estudio "AdReaction: Marketing in a multiscreen world" (2014), elaborado por Milward Brown, ofrece el primer ránking mundial sobre el tiempo que los habitantes por países dedican a ver la televisión, navegar por internet usando el portátil, una computadora de sobremesa, un smartphone o una tableta. En el caso de Brasil la cifra alcanza los 474 minutos diarios, y en España los 397. Aunque el usuario destina a la tableta el tiempo más reducido, con una media de 50 minutos, la expansión del consumo multipantalla es en parte consecuencia directa del aumento de las ventas de nuevos dispositivos. En este sentido, según la consultora IDC, en 2013 se vendieron en España 3,8 millones de tabletas, un millón más que ordenadores y portátiles, logrando una penetración en la población del 26,2 por ciento (eMarketer, 2014). Por su parte, Brasil es el país con el mayor número de usuarios de tabletas en América Latina, con 28 millones de dispositivos en 2014 (Proxxima, 2015), y el segundo desde el punto de vista de la penetración, con un 13,9 por ciento.

Según el informe de Reuters Institute for the Study of Journalism, las tabletas poseen además una estrecha vinculación con el consumo informativo, ya que el 62 por ciento de los usuarios de iPad indican que utilizan el dispositivo para informarse (Newman, \& Levy, 2014).

A pesar de estas cifras, en España no se ha defendido ninguna tesis doctoral que analice el uso periodístico o la acogida entre las audiencias de este tipo de soporte, y los estudios empíricos centrados en las tabletas escasean. En 2010, Larrañaga Rubio describe la ansiedad de los editores ante la llegada de nuevos soportes, como los lectores de libros electrónicos, principalmente el Kindle, y el iPad. De forma genérica, Scolari, Aguado y Feijóo (2013) hablan de la emergencia del medio móvil en la ecología de los medios y proponen una nueva taxonomía de contenidos y aplicaciones para dispositivos móviles, incluso de los medios de comunicación. Cabe destacar también el trabajo realizado desde la Universidad de Coruña sobre la interactividad en las aplicaciones para iPad (Nozal Cantarero, \& González Neira, 2012) y su propuesta de análisis de ediciones vespertinas de prensa para tabletas (Nozal Cantarero, González Neira, y Sanjuán, 2014). Respecto a los estudios de usabilidad aplicados a las tabletas, estos han sido abordados fundamentalmente desde las áreas de la Pedagogía y la Informática.

La escasa atención prestada desde la academia, coincide con el impacto en el sector del dispositivo. Tras el entusiasmo inicial que acompañó el lanzamiento del iPad en 2010, las apuestas de los medios creando productos autóctonos han sido escasas en este terreno, conscientes de los inconvenientes que acompañan al soporte: en primer lugar exige la descarga de una aplicación, pero además estas apps de revistas son invisibles para la web lo que impide que los motores de búsqueda indexen los contenidos de las publicaciones, dificultando su promoción y conocimiento. 


\section{Productos autóctonos}

La situación actual por la que atraviesan las empresas periodísticas se caracteriza por algunas rupturas, principalmente con el desarrollo del periodismo de base de datos (Barbosa, 2009) y la expansión de la convergencia periodística (Gordon, 2003; Quinn, 2005; Salaverría, García Avilés, \& Masip, 2010), en un contexto en el que los dispositivos móviles han obtenido un gran protagonismo. Barbosa (2013) se refiere a este período como la quinta generación del periodismo digital, caracterizada también por la disponibilidad de contenidos en diversos formatos procedentes de organizaciones multiplataforma y una remediación y pos-remediación entre los nuevos y los viejos medios (Bolter \& Grusin, 2000; Grusin, 2010).

En este escenario, surgen aplicaciones periodísticas creadas específicamente para dispositivos móviles, con la finalidad de producir un material exclusivo y que aproveche mejor la potencialidad de las tabletas. Estos productos nativos y autóctonos reflejan una nueva dinámica en los procesos de producción y consumo de noticias en entornos digitales (Barbosa, Firmino da Silva, Nogueira, \& Almeida, 2013), y no reducen su presencia a una versión enriquecida con enlaces, sonido y vídeos de la misma publicación en papel (Torrejón, \& Ocaña, 2011: 23).

Los medios de comunicación diseñados para tabletas, objeto de este estudio, incorporan algunas funciones posibilitadas por el dispositivo (affordances), como la navegación no lineal, el amplio uso de recursos multimedia, galerías de fotos y vídeos, imágenes de $360^{\circ}$, geolocalización, infografías con interacción táctil que incluyen manipulación de los datos y/o de la visualización, entre otros. Representan un estadio avanzado frente a otros productos que reducen su presencia a replicar el medio impreso.

En el seno de esta nueva oferta informativa para tabletas ha surgido el segmento de las publicaciones vespertinas, generalmente ligadas a algún medio de papel, y destinadas a realizar una lectura más prolongada, con un resumen de las noticias más relevantes al final de la jornada, consumidas de forma cómoda y mientras el lector se encuentra reclinado. Es lo que Mario García (2013) ha denominado como "lean-back experience". En Brasil, este tipo de producto ha sido aceptado por el mercado, fundándose por ejemplo $O$ Globo a Mais (del diario $O$ Globo, de Río de Janeiro), Estadão Noite (del Estado de S.Paulo, de São Paulo) y DN Plus (del Diário do Nordeste, de Fortaleza). En España solo había una iniciativa, la del periódico El Mundo, que lanzó en el segundo semestre de 2013 su vespertino El Mundo de la Tarde, y que tras once meses de vida cerró en septiembre de 2014.

En realidad, el caso español se caracteriza principalmente por la aparición de revistas digitales exclusivas para tabletas, de difusión quincenal o mensual. Entre ellas destacan Don, Vis-à-Vis y Quality Sport (esta último comenzó como edición impresa, después pasó a la web y, finalmente, se ha convertido en una publicación digital para dispositivos móviles), aunque recientemente también han nacido nuevos títulos como UnBreak, Magellan o Mine. En agosto de 2014, el diario deportivo Marca también implementó una edición para tabletas quincenal con la denominación de Marca Plus.

Estas publicaciones poseen un carácter experimental, con pequeñas redacciones y profesionales que colaboran como freelance. Algunas de ellas son gestionadas como empresas de nueva creación, con una plantilla joven, algunos de ellos recién gradua- 
dos en las facultades de Comunicación, conscientes de que las oportunidades laborales en las redacciones tradicionales se han reducido drásticamente. Las publicaciones digitales de nueva generación representan una fórmula para divulgar su propio trabajo, experimentar con la interactividad creativa y obtener ingresos a través de la publicidad, presente también por este escenario.

\section{La usabilidad como método científico}

Dentro del campo de la interacción humano-computadora (IHC), la usabilidad representa un aspecto esencial de los estudios cognitivos (Venkatesh \& Agarwal, 2006), que se desarrolla principalmente en la década de 1980, para hacer referencia a la capacidad de un producto o sistema para ser usado de forma sencilla por un segmento específico de usuarios (Santa Rosa \& De Moraes, 2008). Nielsen (2012), uno de los principales teóricos sobre la cuestión, define la usabilidad como un atributo cualitativo que cuantifica la facilidad de uso de una interfaz para el usuario.

El término también sirve para referirse a los métodos empleados para la medición de dicho uso. Independientemente de la metodología, un test de usabilidad pretende obtener datos (tiempo de ejecución, porcentaje de errores y de tareas cumplidas), interpretarlos para identificar los principales problemas del sistema y, al final, sugerir soluciones para corregir los errores (Karampelas, 2013) y que la interacción con el sistema resulte lo más exitosa posible.

El principal objetivo de este test es comprobar si las intenciones del usuario se corresponden con las que perseguía el desarrollador del producto (Wagner, Hassanein \& Head, 2014).

Karampelas (2013) sugiere dos clasificaciones para denominar a los métodos empleados en el test de usabilidad, en función del tipo de participación y del momento en que se ejecuta: métodos empíricos (con la participación del usuario, a través de focus group, cuestionarios, pensamiento en voz alta, observación de campo) y no empíricos (con la participación de especialistas, por medio de validación heurística, inspección de directrices); y los métodos formativos (en cualquier fase del desarrollo del prototipo) y sumativos (con el producto final establecido).

A pesar de su aplicación en estudios de mercado y en investigaciones académicas, los test de usabilidad no han estado exentos de críticas. Bolter y Gromala (2003: 5) sugieren que estos estudios, desarrollados por una corriente de investigadores estructuralistas, mitifican la transparencia:

The mistake that Nielsen and Norman make is to assume that the single goal of all design is to make the interface transparent, when in fact the goal is to establish an appropriate rhythm between being transparent and reflective. This is a common error in mainstream interface design and HCI today. Despite evidence of the popularity of experiential Web sites, computer designers and HCI experts still suppose that the best interface is always "clear", "simple", and "natural." As we shall see, all of these are variations on the theme of the disappearing computer.

Para estos autores, es un error considerar que las interfaces deben ser naturales y transparentes, y opinan que también se deben crear interfaces opacas, en las cuales el 
usuario pueda resolver eventuales problemas cuando el sistema deje de responder o aparezca algún error. En definitiva, para superar el mito, creen que las interfaces deben oscilar entre la transparencia y la opacidad.

\section{Metodología}

\subsection{Selección de los participantes}

No existe consenso sobre el número ideal de participantes que deben emplearse en un estudio sobre usabilidad. Nielsen (2000), por ejemplo, afirma que apenas cinco usuarios son suficientes para detectar el $85 \%$ de los problemas de usabilidad, ya que a partir de esa cifra habrá en muchas ocasiones repetición de comportamientos y, por lo tanto, una pérdida de tiempo en la detección de problemas. Una corriente de autores ha argumentado en contra de dicho procedimiento: algunos investigadores han detectado cálculos inadecuados por el uso de suposiciones erróneas o insuficientes (Woolrych, \& Cockton, 2001); también hay quienes han afirmado haber identificado solo el 35\% de los problemas por utilizar solo a cinco usuarios (Spool, \& Schroeder, 2001).

Relacionado con este debate, se encuentra el argumento de Sauro \& Lewis (2012), para quienes no es tan importante definir la cantidad como identificar una muestra que represente los distintos públicos del sistema a analizar. La definición por grupos de edad puede guiar la elección de la muestra, incluso si el perfil de usuario es distinto en cada país. Por ejemplo, el estudio \#InformeTAB, de la Universidad de La Rioja, detectó que los jóvenes entre 25 y 34 años son quienes más utilizan el iPad, una media de 2 ó 3 horas al día, principalmente para consultar el tiempo, el correo electrónico y leer noticias (Redbility, 2013: 30). Mientras tanto, el Reuters Institute Digital News Report 2014 verificó que, en el Reino Unido, son las personas entre 45 y 54 años quienes más leen noticias en aplicaciones para tabletas, seguidas después de la franja de 35 a 44 años (Newman \& Levy, 2014: 10).

En nuestro caso, se optó por seleccionar una población total de diez participantes, entre los 18 y los 42 años, de España y Brasil, estudiantes de diversos grados y posgrados de la Universidad de Málaga y de la Universidad Federal da Bahía, instituciones involucradas en la investigación. Asimismo, la muestra estaba compuesta por usuarios de tableta y otros que experimentaban por primera vez con el soporte. Fue complicado localizar algún perfil de usuario de publicaciones digitales para tabletas, incluso entre los propios alumnos de Periodismo.

Tabla 1. Perfil de los participantes en el estudio de usabilidad. Fuente: elaboración propia

\begin{tabular}{|l|c|c|c|c|l|}
\hline \multicolumn{7}{|c|}{ ESPAÑA } \\
\hline & Género & Edad & $\begin{array}{c}\text { Usuario/a } \\
\text { de tableta }\end{array}$ & $\begin{array}{c}\text { Lector/a de } \\
\text { revistas }\end{array}$ & \multicolumn{1}{|c|}{ Formación } \\
\hline P1 & Mujer & 31 & Sí & Sí & $\begin{array}{l}\text { Estudiante de doctorado } \\
\text { en Educación y } \\
\text { Comunicación }\end{array}$ \\
\hline P2 & Mujer & 28 & Sí & No & $\begin{array}{l}\text { Estudiante de doctorado } \\
\text { en Biología Celular }\end{array}$ \\
\hline P3 & Varón & 26 & Sí & No & $\begin{array}{l}\text { Estudiante de doctorado } \\
\text { en Biología Celular }\end{array}$ \\
\hline
\end{tabular}




\begin{tabular}{|c|c|c|c|c|c|}
\hline P4 & Mujer & 24 & No & No & $\begin{array}{l}\text { Estudiante de grado en } \\
\text { Periodismo }\end{array}$ \\
\hline P5 & Varón & 21 & No & No & $\begin{array}{l}\text { Estudiante de grado en } \\
\text { Periodismo }\end{array}$ \\
\hline \multicolumn{6}{|c|}{ BRASIL } \\
\hline & Género & Edad & $\begin{array}{l}\text { Usuario/a } \\
\text { de tableta }\end{array}$ & $\begin{array}{l}\text { Lector/a de } \\
\text { revistas }\end{array}$ & Formación \\
\hline P6 & Varón & 23 & Sí & Sí & $\begin{array}{l}\text { Periodista y diseñador } \\
\text { gráfico }\end{array}$ \\
\hline P7 & Varón & 18 & No & No & $\begin{array}{l}\text { Estudiante de grado en } \\
\text { Periodismo }\end{array}$ \\
\hline P8 & Mujer & 42 & No & No & $\begin{array}{l}\text { Pedagoga y licenciada en } \\
\text { Artes Visuales }\end{array}$ \\
\hline P9 & Mujer & 27 & No & No & $\begin{array}{l}\text { Estudiante de grado en } \\
\text { Periodismo }\end{array}$ \\
\hline $\begin{array}{c}\mathrm{P} 1 \\
0\end{array}$ & Varón & 25 & No & No & $\begin{array}{l}\text { Estudiante de grado en } \\
\text { Periodismo }\end{array}$ \\
\hline
\end{tabular}

\subsection{Protocolo}

Para el diseño del protocolo se tomó como referencia el experimento realizado por Gatsou, Politis, y Zevgolis (2013) y se adaptó al contexto de nuestro estudio. Antes del inicio de cada sesión, cada participante recibió una explicación sobre el experimento al que sería sometido, con objeto de que entendiera la finalidad del estudio. Una vez comprendido el procedimiento, $\mathrm{y}$ tras manifestar su consentimiento para participar en la investigación, se aplicó un protocolo para obtener su permiso para la grabación audiovisual durante la navegación que realizara por las tres publicaciones seleccionadas.

En las grabaciones se incluyó el audio para tener constancia de los comentarios de los usuarios y, respecto a la imagen, no se reconocían rostros, ya que la ubicación de la cámara solo captó primeros planos de las manos y el iPad. Cada participante fue grabado en sesiones de 40 minutos en los platós de televisión de la Facultad de Ciencias de la Comunicación, en la Universidad de Málaga (España), entre los días 26 de mayo y 10 de junio de 2014, y en la Facultad de Comunicación de la Universidad Federal de Bahía (Brasil), entre los días 26 y 30 de septiembre de 2014.

Todos los participantes fueron estudiados individualmente, de forma aislada, solo acompañados por el investigador que conducía las tareas del usuario. El técnico responsable de la grabación estaba ubicado fuera del escenario, en la sala de control.

Para minimizar el sesgo de aprendizaje en el manejo del dispositivo, el investigador que solicitaba las tareas fue alternando el orden de las revistas a analizar, para que ningún medio quedara perjudicado por la potencial inexperiencia del usuario. Los videos resultantes de las grabaciones de los experimentos fueron para uso exclusivo de los investigadores, con el propósito de revisar los resultados de las pruebas de usabilidad.

La sesión experimental con cada medio se dividió en tres partes: en la primera el participante disponía de cinco minutos de uso libre de una edición de la revista, distinta a la que sería evaluada; en la segunda fase se ejecutaban cinco tareas sobre una edición 
de la revista predeterminada, las cuales eran cronometradas por el investigador quien también comprobaba si se concluían o si quedaban incompletas; $y$, en la última fase, el usuario rellenaba un cuestionario sobre la experiencia vivida durante la navegación. Las tres fases se repitieron con cada medio analizado y con todos los participantes.

\subsection{Material}

Además de una cámara Full-HD para registrar el movimiento de las manos sobre la pantalla de la tableta utilizada, también fue necesario un micrófono de solapa para registrar los comentarios realizados por el usuario durante la navegación. El modelo de tableta empleado para la investigación fue un iPad de tercera generación, con pantalla retina, que posibilita visualizaciones de alta resolución, con el doble de píxeles que los modelos anteriores.

\subsection{Selección de las aplicaciones}

El criterio seguido para la elección de las aplicaciones a evaluar en el presente estudio fue escoger medios que se caracterizaran por un intenso uso de los recursos que potencial y objetivamente acompañan a estos dispositivos y, especialmente, la aplicación de funciones multimedia como la galería de fotos y vídeos, gráficos y animaciones. Además, las aplicaciones también debían tener varias opciones de exploración (páginas vistas en miniatura, hipervínculos, interacción a través de los botones). Como hipótesis de partida, pensamos que los productos diseñados exclusivamente para tableta podrían utilizar mejor este tipo de características, a la vez que podían estar abiertas a un mayor grado de experimentación. También se decidió que los usuarios evaluaran medios escritos en su misma lengua materna, para que el sesgo del idioma no pudiese afectar a los resultados.

En España se detectaron tres casos que pueden enmarcarse en la categoría de revistas digitales exclusivas para tableta, surgidas a partir de una corriente de start-ups de pequeñas e innovadoras empresas periodísticas, que nacen como consecuencia de la crisis de los medios tradicionales de comunicación y la escasa posibilidad de encontrar empleo en ellos. Este nuevo ecosistema de medios generalmente requiere de pequeñas oficinas, con un número también reducido de periodistas y colaboradores, $\mathrm{y}$ con una difusión mensual. Para este estudio se utilizaron tres publicaciones con sede en Madrid: Don (edición 5), Quality Sport (edición 20) y Vis-à-Vis (edición 23), y el estudio se usabilidad se centró en sus ediciones de marzo de 2014. Para la navegación libre del usuario, se utilizaron ediciones posteriores, de mayo de 2014.

En Brasil, país en desarrollo donde la venta de publicaciones tradicionales sigue siendo representativa, la apuesta por las ediciones para tableta es diferente al caso español. Son las mismas empresas tradicionales las que han decidido invertir en productos exclusivos para tabletas trasladando su know how y experiencia al nuevo soporte. Con el resurgimiento de los vespertinos digitales, productos que salen al finalizar la jornada con un resumen de las noticias, cada periódico pretende lanzar su marca y crear equipos exclusivos para producir el material de estos productos autóctonos (Canavilhas \& Satuf, 2013; Barbosa et al., 2013). Para este estudio se escogieron las publicaciones O Globo a Mais, de Río de Janeiro; Estadão Noite, de Sao Paulo; y Diário do Nordeste Plus, de Fortaleza. 


\subsection{Tareas}

La segunda etapa del experimento consistió en la ejecución de cinco tareas en cada uno de los productos analizados, con objeto de explorar las habilidades necesarias para la navegación, la interacción y el aprendizaje del sistema diseñado. Cada tarea fue cronometrada para cuantificar el tiempo que el usuario necesitaba para cumplir (o no) una actividad. Durante la prueba, solo se permitió repetir una vez más la tarea y pasar a la siguiente cuando no se había obtenido éxito después de tres minutos de intentos. Las tareas pretendían determinar la complejidad de los contenidos y la presentación de los recursos multimedia de cada publicación. En la tabla 2 se relacionan las tareas solicitadas a cada usuario, por publicación:

Tabla 2. Tareas realizadas por cada usuario en la segunda fase del experimento.

Fuente: elaboración propia

\begin{tabular}{|c|}
\hline DON, ED. 5, MARZO 2014, “MODA A LO BESTIA!” \\
\hline $\begin{array}{l}\text { 1. Entre en la edición de marzo de } 2014 \text { y busque la sección "Ding Don"; } \\
\text { 2. Busque la sección "Ases del Humor" y haga clic en el enlace sobre Mark Twain; } \\
\text { 3. Localice el otro índice, en la sección "Revista"; Busque el reportaje sobre "Premios Vida" } \\
\text { y pulse para ver el vídeo completo sobre el primer proyecto; y } \\
\text { 4. En este mismo reportaje, pulse para ver más informaciónes sobre el autor del segundo } \\
\text { proyecto. }\end{array}$ \\
\hline QUALITY SPORT, ED. 20, MARZO 2014, "MARADONA" \\
\hline $\begin{array}{l}\text { 1. Entre en la edición de marzo y busque el reportaje de portada sobre Maradona; } \\
\text { 2. En este reportaje de Maradona, reproduzca nuevamente el audio; } \\
\text { 3. En este mismo reportaje, ejecute el vídeo para ver el mejor gol del jugador; } \\
\text { 4. Busque el primer reportaje de la sección "Radar" y lea el texto sobre el Mundial de } \\
\text { Fórmula } 1 ; \text { y } \\
\text { 5. Busque el enlace de la cuenta de Twitter que permite seguir a Quality Sport. }\end{array}$ \\
\hline VIS-À-VIS, ED. 23, MARZO 2014, "BIMBA: CIAO BAMBINA!” \\
\hline $\begin{array}{l}\text { 1. Entre en la edición de marzo y busque la sección "Cultura"; } \\
\text { 2. Busque la sección "Cultura", localice el primer reportaje de esta sección y reproduzca el } \\
\text { vídeo de la película "American Express (2006)"; } \\
\text { 3. Busque la sección "Inbox" y llegue a la última foto de la selección de imágenes; } \\
\text { 4. Busque el reportaje "Salvajes y Corruptos" y vea la foto de Jim Morrison; y } \\
\text { 5. Busque la sección Editorial y comparta la página por correo. }\end{array}$ \\
\hline O GLOBO A MAIS, 23 SEPTIEMBRE 2014, "JOGO FEITO, BANCA FORTE" \\
\hline $\begin{array}{l}\text { 1. Entre na edição de } 23 \text { de setembro e busque a seção "Giro"; } \\
\text { 2. Nesta seção, clique no único link do texto "Linhas de Hong Kong"; } \\
\text { 3. Na seção "Imagens do Dia", visualize a última fotografia de forma ampliada; } \\
\text { 4. Na reportagem de capa "Próximo Pote de Ouro", descubra quem é o protagonista da } \\
\text { matéria; y } \\
\text { 5. Busque a seção "Imagem a Mais" e guarde a página nos favoritos do aplicativo. }\end{array}$ \\
\hline ESTADÃO NOITE, 23 SEPTIEMBRE 2014 \\
\hline $\begin{array}{l}\text { 1. Entre na edição de } 23 \text { de setembro e descubra a legenda da foto de capa; } \\
\text { 2. No artigo de "Marco Antonio Carvalho" visualize o final do texto; } \\
\text { 3. Na seção "Cenas do Dia", comparta a primeira fotografia por e-mail; } \\
\text { 4. Na seção "TV Estadão", veja o vídeo sobre a banda Cachorro Grande; y } \\
\text { 5. Visualize, dentro do aplicativo, as últimas notícias do site do Estadão. }\end{array}$ \\
\hline DIÁRIO DO NORDESTE PLUS, 23 SEPTIEMBRE 2014, "VIDA DE TÉCNICO” \\
\hline $\begin{array}{l}\text { 1. Entre na edição de } 23 \text { de setembro e busque a seção "Panorama"; } \\
\text { 2. Nesta seção, visualize a terceira matéria desta tela inicial; } \\
\text { 3. Visualize as páginas desta edição no formato miniatura; } \\
\text { 4. Na coluna de "Marlyana Lima", visualize o vídeo sobre a Saison Saúda; y } \\
\text { 5. Nesta mesma coluna, conheça e exiba todos os sabores mais exóticos. }\end{array}$ \\
\hline
\end{tabular}




\subsection{Cuestionario post-test}

Para detectar y cuantificar los potenciales problemas existentes entre las aplicaciones testadas, los participantes también completaron un cuestionario tras ejecutar las tareas. Esta herramienta está basada en el System Usability Scale (SUS), metodología desarrollada por Brooke (1996). Inicialmente, se trata de un cuestionario con diez afirmaciones, a las cuales los usuarios le atribuyen entre uno y cinco puntos, respetando la escala Likert, para conocer si apoyan o si están en desacuerdo con dichas afirmaciones.

Tras barajar una serie de alternativas, el SUS se consideró la opción más pertinente primero por su flexibilidad para analizar la usabilidad de las tecnologías más diversas, ya sean interfaces o plataformas; y, otra razón para su elección, es su fácil entendimiento tanto para los participantes como para los investigadores. Finalmente, también se trata de una herramienta sin propietarios y cuyo diseño requiere de un coste bajo.

Tras responder numéricamente a las diez afirmaciones, se realizó una fórmula. En las afirmaciones positivas se restó un punto de lo otorgado (por ejemplo, si el usuario marcó 3, el investigador le considera para el cálculo 2), mientras en las afirmaciones negativas se sustraían cinco puntos. Al final, se sumaron las puntuaciones afirmativas para obtener una escala de 0 a 100, donde el mayor número indica los productos con mejor usabilidad.

La flexibilidad permitida por el método nos permitió realizar algunas adaptaciones para este estudio. Primero, cambiar el término "sistema" por "aplicación", "revista" o "publicación", para adecuarlo directamente al objeto de estudio. Después, al percibir que algunas cuestiones parecían repetitivas, las sustituimos por otras cuestiones que estaban directamente más relacionadas con la investigación. En la tabla 3 se realiza la comparación entre el cuestionario original y el que finalmente se aplicó en este estudio:

Tabla 3. Cuestionario SUS original vs. cuestionario adaptado para el estudio.

Fuente: elaboración propia

\begin{tabular}{|l|l|}
\hline \multicolumn{1}{|c|}{ CUESTIONARIO ORIGINAL } & \multicolumn{1}{c|}{ CUESTIONARIO ADAPTADO } \\
\hline $\begin{array}{l}\text { 1. I think that I would like to use this system } \\
\text { frequently. (positivo) }\end{array}$ & $\begin{array}{l}\text { 1. Me ha gustado la experiencia de navegar por } \\
\text { esta revista. (positivo) }\end{array}$ \\
\hline $\begin{array}{l}\text { 2. I found the system unnecessarily complex. } \\
\text { (negativo) }\end{array}$ & $\begin{array}{l}\text { 2. Si tuviere tableta, me convertiría en } \\
\text { lector habitual de esta revista. (positivo) }\end{array}$ \\
\hline 3. I thought the system was easy to use. (positivo) & $\begin{array}{l}\text { 3. La navegación por la revista me parece muy } \\
\text { compleja. (negativo) }\end{array}$ \\
\hline $\begin{array}{l}\text { 4. I think that I would need the support } \\
\text { of a technical person to be able to use } \\
\text { this system. (negativo) }\end{array}$ & $\begin{array}{l}\text { 4. Antes del experimento, pensaba que la } \\
\text { navegación por revistas para iPad era más } \\
\text { sencilla. (negativo) }\end{array}$ \\
\hline $\begin{array}{l}\text { 5. I found the various funcions in this system were } \\
\text { well integrated. (positivo) }\end{array}$ & $\begin{array}{l}\text { 5. Creo necesaria una ayuda para recorrer la } \\
\text { revista (tutorial, chat, experto). (negativo) }\end{array}$ \\
\hline $\begin{array}{l}\text { 6. I thought there was too much inconsistency in } \\
\text { this system. (negativo) }\end{array}$ & $\begin{array}{l}\text { 6. La estructura de la revista me ha parecido } \\
\text { caótica. (negativo) }\end{array}$ \\
\hline $\begin{array}{l}\text { 7. I would imagine that most people would learn } \\
\text { to use this system very quickly. (positivo) }\end{array}$ & $\begin{array}{l}\text { 7. Considero que la mayoría de las personas } \\
\text { aprenderían muy rápidamente a usar la revista. } \\
\text { (positivo) }\end{array}$ \\
\hline $\begin{array}{l}\text { 8. I found the system very cumbersometo use. } \\
\text { (negativo) }\end{array}$ & $\begin{array}{l}\text { 8. Creo que hay demasiados elementos } \\
\text { audiovisuales, lo que puede distraer y /o } \\
\text { ralentizar la lectura. (negativo) }\end{array}$ \\
\hline
\end{tabular}




\begin{tabular}{|l|l|}
\hline 9. I felt very confident using the system. (positivo) & $\begin{array}{l}\text { 9. Me ha incomodado la publicidad } \\
\text { (por cantidad y /o tipología). (negativo) }\end{array}$ \\
\hline $\begin{array}{l}\text { 10. I needed to learn a lot of things before I could } \\
\text { get going with this system. (negativo) }\end{array}$ & $\begin{array}{l}\text { 10. El tamaño del texto me parece } \\
\text { incómodo. (negativo) }\end{array}$ \\
\hline
\end{tabular}

En usos previos, investigadores del cuestionario SUS fijaron una media de 68 puntos como el ideal de la usabilidad. Al realizar una propuesta modificada y, por tanto, una experiencia piloto, se ha procurado no determinar una puntuación ideal. El cuestionario original también posee un equilibrio entre afirmaciones negativas y afirmativas (relación 50/50), presentadas de forma alternada como se aprecia en la tabla 3 , mientras que nuestras afirmaciones tienden a ser más negativas (30/70). De todos modos, se consideraron como en el cálculo de puntuación de SUS, y se restó cinco puntos en este tipo de afirmaciones.

\section{Resultados}

\subsection{Tareas}

Durante el test de usabilidad, cada participante ejecutó cinco tareas por cada una de las tres publicaciones analizadas. En total, cada individuo asumió quince tareas. A la ejecución de cada tarea el investigador le asignó una de las siguientes posibilidades: una tarea bien realizada; una tarea completada con ayuda del investigador, y una tarea no cumplida (en este último caso, se decidió continuar con la siguiente tarea cuando el usuario lo solicitaba o cuando, después de tres minutos sin alcanzar el objetivo solicitado, el investigador le daba la posibilidad de pasar a la siguiente prueba). Esta última situación solo ocurrió en una tarea de la revista Vis-à-Vis, cuando el participante necesitaba buscar y ejecutar un vídeo escondido en el primer reportaje de la sección Cultura, en el que era necesario leer la continuidad del texto haciendo uso de un scroll y posteriormente seleccionar algunos botones numéricos para localizar la visualización del vídeo.

Gráfico 1. Porcentaje de tareas realizadas y no realizadas. Fuente: elaboración propia

En Brasil

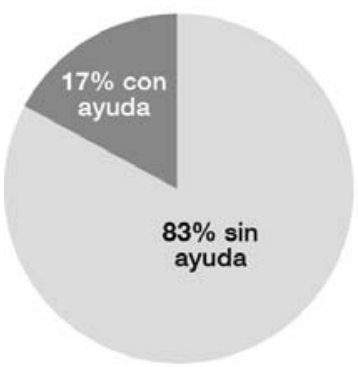

En España

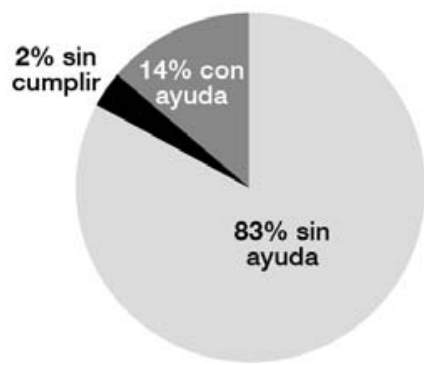

Al observar el gráfico 1, se detectan semejanzas en relación a la cantidad de tareas cumplidas sin apoyo del investigador (83\%). Las publicaciones que no requirieron de esta ayuda fueron Estadão Noite y Quality Sport. Ambos medios poseen rasgos comunes: ofrecen pocos contenidos y, consecuentemente, las tareas pueden ser ejecutadas de una forma más sencilla. 


\subsection{Publicidad}

El reducido tamaño de la pantalla de las tabletas genera un nuevo reto para la organización de los elementos, tanto para definir una nueva narrativa del contenido editorial como para desarrollar nuevos formatos publicitarios. En el caso de las revistas, el contenido informativo y el publicitario luchan por captar la atención del lector, con la complicación de que no existen bordes que diferencien dichos espacios. La participante 4 (Yolanda) comentó durante la navegación que tenía dificultades para distinguir qué era publicidad y qué era noticia, ya que ambos exploran los mismos recursos de interactividad y multimedialidad, asemejándose formalmente.

En el cuestionario pos-test, una de las afirmaciones abordaba directamente esta cuestión: "Me ha incomodado la publicidad (por cantidad y/o tipología)". Los participantes respondían una escala Likert donde 1 significaba en completo desacuerdo y 5, completamente de acuerdo. Como resultado, hubo una correlación entre las evaluaciones de los usuarios y la cantidad de publicidad alojada en las publicaciones analizadas. El caso más evidente fue el de $O$ Globo a Mais, cuya edición tiene un promedio de 20 pantallas, siendo siete de ellas de anuncios publicitarios. Por ello la respuesta del usuario osciló entre 3 (regular) e 5 (completamente de acuerdo). En el Diário do Nordeste Plus las respuestas se centraron en la primera opción de la escala Likert (en completo desacuerdo), ya que tanto en esta publicación como en Estadão Noite no aparecían espacios publicitarios, o su presencia se reducía a la página de inicio.

Tabla 4. Presencia de la publicidad en las publicaciones analizadas y respuesta de los usuarios ante la afirmación "Me ha incomodado la publicidad" (SUS). Fuente: elaboración propia

\begin{tabular}{|l|r|r|}
\hline PUBLICACIÓN & PUBLICIDAD \% & MEDIA LIKERT \\
\hline O Globo a Mais & $31 \%$ & 3,6 \\
\hline Vis-à-Vis & $11,2 \%$ & 3,4 \\
\hline Revista Don & $6,1 \%$ & 2,6 \\
\hline Quality Sport & $3,1 \%$ & 2,0 \\
\hline Estadão Noite & - & 1,2 \\
\hline DN Plus & - & 1,0 \\
\hline
\end{tabular}

\subsection{Cuestionario}

Después de navegar por cada publicación, los participantes respondían un cuestionario basado en la escala Likert, con un cálculo obtenido mediante la metodología SUS (System Usability Scale). El principal resultado de este apartado es que prevalece la filosofías de "menos es más", pues las publicaciones más simples en términos de contenido e interacción presentan las mejores valoraciones por parte de los usuarios. Las revistas brasileñas, diarias, con menos contenidos que las publicaciones mensuales españolas, obtuvieron los mejores resultados, como indica el gráfico 2. 
Gráfico 2. Puntuación obtenida por los medios en el cuestionario pos-test (SUS).

Fuente: elaboración propia
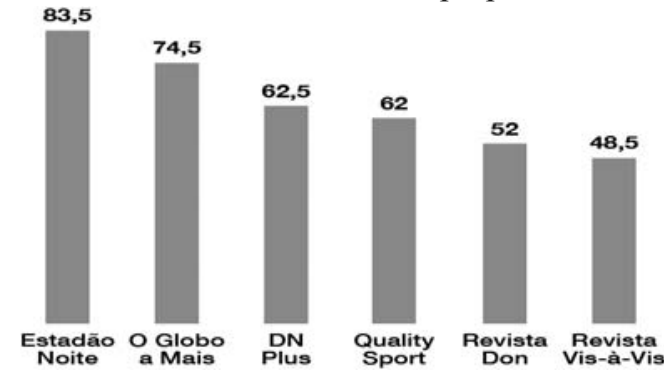

Esta ha sido una de las escasas correlaciones detectadas en la investigación. Otros factores como la edad, la formación o la experiencia en el uso de tabletas no presentaron analogías entre sí. De forma general, todos pasaron por las mismas dificultades y facilidades en la ejecución de tareas. La única excepción fue el participante 6 (Marcelo), una de las pocas personas empleadas en la muestra con experiencia en navegación en publicaciones digitales, que incluso conocía la revista $O$ Globo a Mais, utilizada en la prueba.

\subsection{Navegación}

La lectura predominante en las publicaciones para tableta es la lineal. Los participantes leen y buscan reportajes y secciones pasando las páginas de izquierda a derecha, como el consumo de un medio tradicional en papel. Esta práctica instintiva de navegación era superada cuando descubrían la visualización en miniatura de las páginas, que permitía cumplir las tareas más rápidamente.
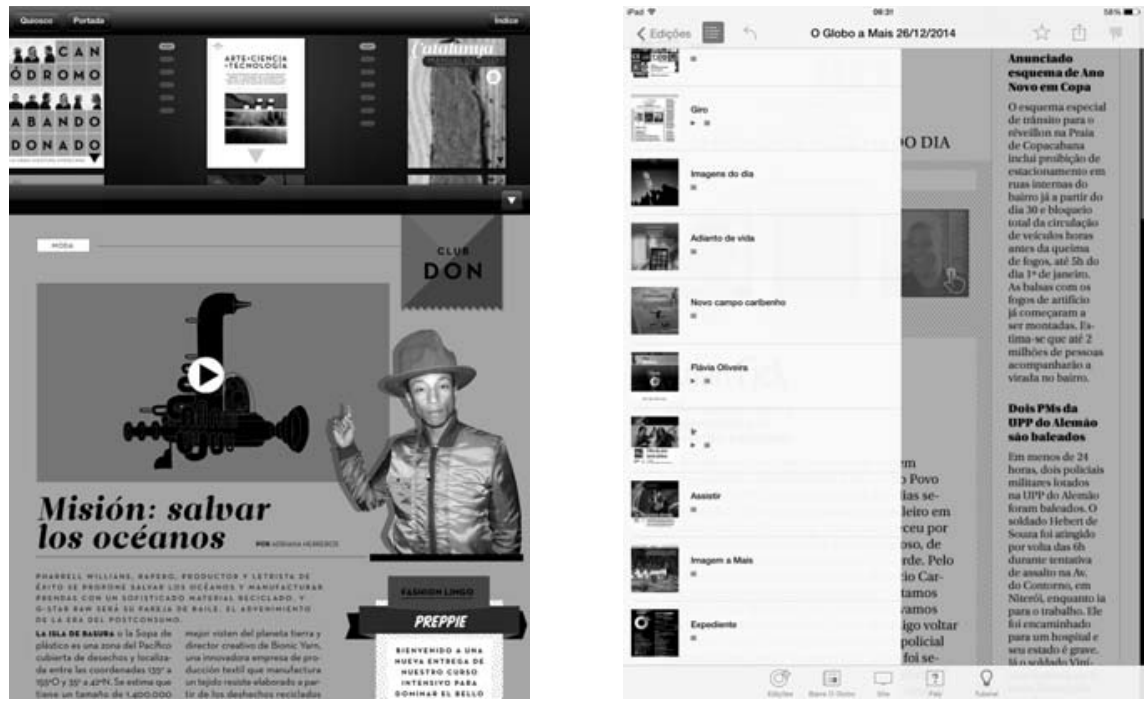

Imágenes 1 y 2. Los usuarios menos expertos prefieren la navegación a través de las miniaturas cuando descubren esa opción. Sin embargo, el índice lateral fue escasamente utilizado 
El único inconveniente detectado en las miniaturas de las publicaciones, concretamente en las españolas Vis-à-Vis y Revista Don, era la falta de descripción sobre cada página. Los usuarios se esforzaban en intentar ver el nombre de la sección dentro de cada página en miniatura para cumplir con la búsqueda exigida en las tareas. Cuando no conseguían ver las miniaturas, entraban en cualquier página y regresaban a la lectura lineal.

El participante 7 (Marcelo), que era el usuario con más experiencia, fue el único en realizar búsquedas a través del menú lateral, que se desplegaba presionando un icono en la barra superior. Este opción de navegación es típica de las publicaciones que utilizan el sistema Adobe, como ocurre en el caso de las brasileñas $O$ Globo a Mais y Estadão Noite. El participante 10 (Venilson) descubrió otro menú lateral oculto en la portada de $O$ Globo a Mais, al hacer clic en "Índice", localizado dentro del logotipo de la revista digital. En este caso se trata de un enlace poco evidente, porque no se asemeja visualmente a un botón, lo que no invita a la interacción ni sugiere la existencia de un menú oculto.

\subsection{Botones y gestos}

Un factor que incomodaba a los participantes durante la navegación eran los botones que no funcionaban. En muchas ocasiones eran pictogramas que indicaban una dirección de lectura de continuidad del reportaje, pero que eran interpretados como botones interactivos. Este es un problema que debiera ser resuelto por las publicaciones, para encontrar una mejor manera de traducirle al lector la intencionalidad y/o la función de las figuras insertas en la diagramación de las páginas.

Fue más frustrante para los lectores que participaron en el test las páginas que parecían incluir enlaces a los contenidos, como la portada de Quality Sport, que no llevaba al tema principal; y también el contenido sobre los "Premios Vida", en la Revista Don, cuya página de apertura recogía imágenes animadas sobre cada proyecto e, intuitivamente, los participantes querían pulsar sobre cada una, pero no ocurría nada.

Con relación a los comandos existentes para la interacción con las revistas, estos no representaron un grave problema para la mayoría de los usuarios, más allá de una cuestión básica y común aludida en otros estudios de usabilidad, y es que los gestos más complejos obligan al usuario a aprender y memorizar unas rutinas de uso que no se transfieren a otras publicaciones. A pesar de esta barrera del aprendizaje, que puede dificultar la accesibilidad a los contenidos, cada aplicación utiliza su propio repertorio de navegación y gestos.

Dos problemas de malinterpretación ocurrieron con la participante 8 (Ana María), la usuaria de mayor edad. El primer error ocurrió durante una tarea de $O$ Globo a Mais ("En la sección 'Imágenes del Día', visualice la última fotografía de forma ampliada"). Para cumplirla, la usuaria debía girar la tableta. Sin embargo, la participante interpretó inicialmente que lo que debía hacer era girar solo la imagen, para lo que utilizó sus dedos como pinzas. El comando facilitado por la revista ("gire para expandir") provocó esa duda.

El segundo problema fue con Estadão Noite, durante la navegación de los cinco primeros minutos. La participante 8 quiso leer la continuidad del artículo, pero no 
conseguía desplazarse para visualizar el resto del texto. El comando "role para ler mais" [scroll para leer más], bajo el texto, no dejaba claro si el lector necesitaba desplazarse en un punto específico de la página. La participante intentó hacer scroll en áreas que no eran textuales, y no pasaba nada.

\subsection{Multimedia: vídeos $y$ animaciones}

Durante los primeros cinco minutos de contacto con cada publicación, a los participantes les resultaron atractivos los vídeos y las páginas con animación. Esta percepción fue más acentuada en el caso de las publicaciones españolas, que exploran con más intensidad estos recursos. Las revistas brasileñas han creado secciones específicas para alojar este tipo de contenidos, como los consejos culturales que incluyen la visualización de clips musicales o trailers de películas.

En el caso de España, por ejemplo, la participante 2 (Alejandra) dedicó más de siete minutos a visualizar vídeos y páginas con animación, interactuando con secciones como "Paradón", en la revista Don, donde el usuario responde a cuestionarios de carácter divertido. Don también apuesta por insertar vídeos en los reportajes de portada, tanto en su presentación inicial como en las páginas internas. Los participantes 1 (Virginia) y 5 (Manuel) estuvieron entre tres y cuatro minutos visionando este tipo de contenidos. El resto dedicó menos de dos minutos, en parte porque su navegación era más ansiosa, ya que pulsaban todos los enlaces e intentaban ver el mayor número de páginas posibles con objeto de familiarizarse con la aplicación y ser más ágiles en las posteriores tareas. Por este motivo no se preocuparon mucho por ver los vídeos en su totalidad. En Brasil, esta cifra también fue inferior a los dos minutos, lo que se explica por la escasa presencia del vídeo como recurso en las publicaciones.

\subsection{Multimedia: galería de imágenes}

El consumo de las galerías de imágenes merece ser analizado de forma independiente. La mayoría de las publicaciones estudiadas prioriza la lectura en sentido vertical, por influencia de las revistas impresas. Las páginas con galerías de imágenes ofrecen la posibilidad de ver la fotos también en modo horizontal. El problema radica en la sincronización de ambos modos de visualización; es decir, cuando se ve la galería en vertical, el usuario espera poder ver la fotografía escogida también adaptada, en vertical.

En el caso de Diário do Nordeste Plus, la galería de fotos, en modo vertical, presenta un mosaico con todas las imágenes en miniatura. La participante 9 (Emile), por ejemplo, pulsaba sobre las miniaturas con la expectativa de verla ampliada en ese espacio, pero solo aparecía cuando cambiaba la pantalla de orientación. Además al girar la tableta, la participante siempre veía la primera foto de la galería, necesitando pasar de una a una cada imagen en la orientación horizontal hasta llegar a la deseada. En $O$ Globo a Mais existe la posibilidad de pasar las fotografías en modo vertical, pero cuando se gira la tableta siempre se regresa a la primera imagen automáticamente, lo que exige al usuario recorrer de nuevo la galería.

En el caso de la galería de la sección Inbox, en la revista Vis-à-Vis, la interfaz es similar a la de DN Plus: con miniaturas de fotos en la orientación vertical y con la opción de verla ampliada en el modo horizontal, obligando a pasarlas individualmente. 
Sin embargo, si el usuario desplaza la fotografía hacia el lateral, que era bastante común en la prueba, se salían de la sección. Las fotografías tenían que ser rodadas hacia abajo, según indicaba un icono triangular en la parte inferior derecha, que quedaba fuera de la zona de impacto visual de la página.
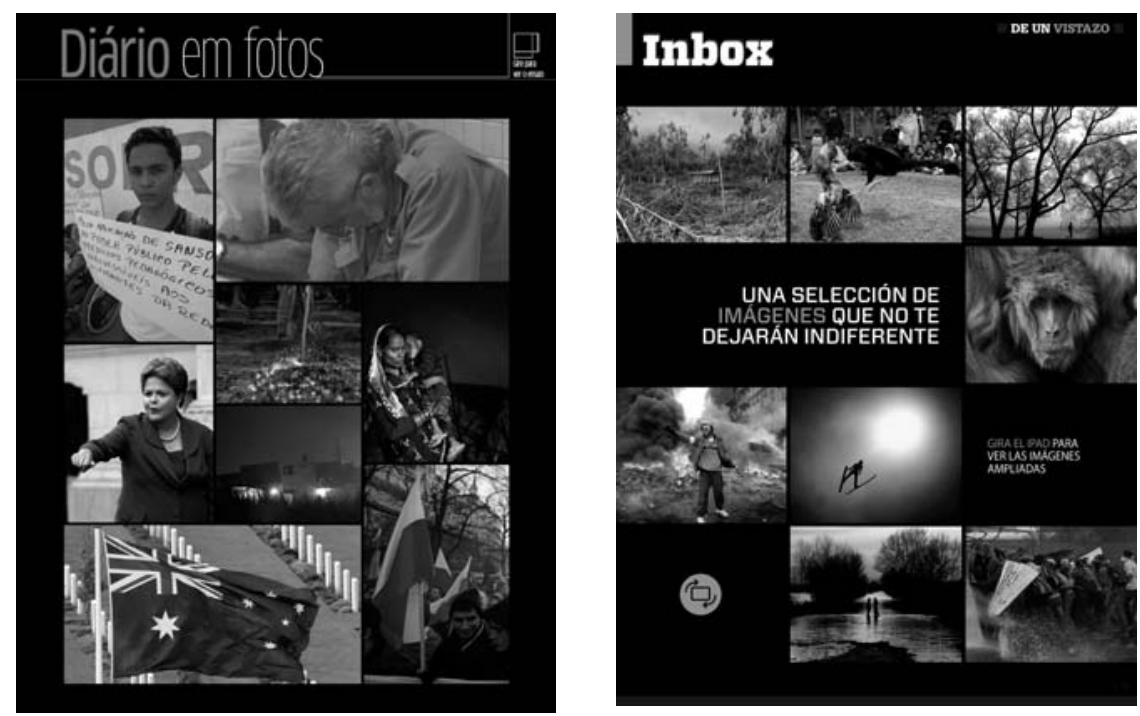

Imágenes 3 y 4 . Las fotos en miniatura de las galerías de imágenes en modo vertical generan confusión en los participantes que necesitaban verlas de forma ampliada

\subsection{Tutoriales}

Como se preveía, durante la prueba se detectó un predominio del usuario de tipo "laico", que según la clasificación sugerida por Santaella (2004: 59), son aquellos que saben entrar en la red, han memorizado algunas rutas específicas, pero no han adquirido ninguna familiaridad ni competencia del experto que conoce los secretos de cada mínima señal que aparece en la pantalla. Debido a esta inseguridad, presente en los usuarios que utilizaban una tableta por primera vez durante esta prueba, resultó fundamental la existencia de un tutorial que facilitaba entender todas las señales presentes en las páginas y la forma de navegación.

Los participantes, incluso aquellos que ya poseían tableta pero no la costumbre de leer revistas en el dispositivo, dedicaron un minuto a leer las páginas del tutorial de las revistas, y regresaban a esta ayuda para intentar esclarecer alguna tarea que no conseguían cumplir. El participante 9 (Bruno), por ejemplo, recorrió el tutorial de Diário do Nordeste Plus para intentar saber cómo visualizar las páginas en miniatura -una de las tareas-, con objeto de obtener también una compresión general de la estructura de la publicación, pero no tuvo éxito pues el manual no contenía ninguna mención sobre esa cuestión, al contrario de las otras publicaciones brasileñas.

Otra sugerencia de mejora es la que realizan a la revista Quality Sport, por poseer un tutorial escondido al final de la página de expediente, al contrario de las otras publicaciones que dedican una página exclusivamente para explicar la funcionalidad de los co- 
mandos de navegación. En este sentido, si el lector de Quality no se desplaza hacia la parte inferior de la página de expediente, no localiza el manual de instrucciones.

\section{Conclusiones}

Las publicaciones para tabletas funcionan como "cajas negras"; con muchos elementos ocultos que necesitan ser revelados por los lectores para conseguir explorar un contenido escondido por puertas ocultas. A pesar de la expansión de las audiencias activas, en muchas ocasiones los usuarios no tienen éxito localizando dichos contenidos. La simplicidad es aun la clave para el mejor uso de los materiales.

Las publicaciones para tableta analizadas en Brasil poseen tres características comunes: ofrecen menos contenidos, menos páginas y son más tímidas en el uso de la interactividad y los recursos multimedia. Sin embargo, los resultados en los test de usabilidad son más positivos que los obtenidos por los medios españoles, de lo que se puede concluir que una economía de contenido y de recursos interactivos está correlacionada con una mayor satisfacción de los usuarios. En este caso, menos es más.

La revista española Vis-a-Vis presenta la navegación más compleja para los usuarios. El tiempo para completar las cinco tareas oscila entre los 5 y los 10 minutos, y es la única publicación donde algunos participantes no han podido completar una tarea, concretamente la que solicitaba que buscaran la sección "Cultura", localizaran el primer reportaje de esta sección y reprodujeran el vídeo de la película "American Express (2006)". Quality Sport, a pesar de estar especializada en el ámbito deportivo, es la que ha presentado una navegación más ágil, y el tiempo medio para superar todas las tareas ha sido de 1'38".

A pesar de los distintos perfiles de los participantes, los tiempos más elevados en los que se han ejecutado las tareas se han repartido equilibradamente, sin influir su experiencia previa en el uso de tabletas. De hecho, quienes menos han tardado en completar las tareas han sido precisamente los usuarios que por primera vez utilizaban este dispositivo móvil.

En el caso brasileño, los resultados son más predecibles. El usuario con más edad y sin experiencia en el manejo de tabletas es quien invierte más tiempo en la ejecución de las tareas (más de doce minutos); mientras el único usuario de tableta y consumidor de revistas digitales es el más rápido (3'52").

\section{Referencias bibliográficas}

ALONSO DEL BARRIO, Estrella (2013): "Interactividad y participación en los medios adaptados para tabletas: las posibilidades del periodismo 3.0". Estudios sobre el Mensaje Periodístico, vol. 19, especial marzo, pp. 35-44. Madrid, Servicio de Publicaciones de la Universidad Complutense.

BARBOSA, Suzana (2009): "Modelo JDBD e o ciberjornalismo de quarta geração", en FLORES VIVAR, José Miguel y ESTEVE RAMÍREZ, Francisco: Periodismo Web 2.0. Madrid, Editorial Fragua, pp. 271-283.

BARBOSA, Suzana (2013): “Jornalismo convergente e continuum multimídia na quinta geração do jornalismo nas redes digitais", en CANAVILHAS, João (Ed.): 
Notícias e mobilidade: o jornalismo na era dos dispositivos móveis. Covilhã, Livros LabCom, pp. 33-54.

BARBOSA, Suzana; FIRMINO DA SILVA; Fernando, NOGUEIRA, Leila; and ALMEIDA, Yuri (2013): "Jornalistic activity on mobile platforms: a study on autochthonous products and changes to the journalist's professional profile". Brazilian Journalism Review, vol. 9, num. 2, pp. 10-29.

BOLTER, Jay David and GROMALA, Diane (2003): Windows and mirrors. Cambridge, MIT Press.

BOLTER, Jay David and GRUSIN, Richard (2000): Remediation: understanding new media. Cambridge, MIT Press.

BROOKE, John (1996): "SUS: a 'quick and dirty' usability scale", in JORDAN, Patrick; THOMAS, Bruce; WEERDMEESTER, Bernard; and McCLELLAND, Ian: Usability evaluation in industry. London, Taylor \& Francis, pp. 107-114.

CANAVILHAS, João y SATUF, Ivan (2013): “Jornalismo em transição: do papel ao tablet... ao final da tarde", en FIDALGO, António y CANAVILHAS, João (Eds.): Comunicação digital: 10 anos de investigação. Coimbra, Minerva, pp. 35-60.

eMARTETER (2014): "The UK leads the EU-5 in Tablet Adoption", http://www.emarketer.com/Article/UK-Leads-EU-5-Tablet-Adoption/1010810 [Consulta: 3 de marzo de 2015]

GARCÍA, Mario (2012): iPad Design Lab: storytelling in the age of the tablet. [edición para iBooks]

GATSOU, Chrysoula; POLITIS, Anastasios; and ZEVGOLIS, Dimitrios (2013): "Exploring inexperienced user performance of a mobile tablet application through usability testing", in FedCSIS: Proceedings of the 2013 Federated Conference on Computer Science and Information Systems. Cracovia, IEEE, pp. 557-564.

GORDON, Rich (2003): "Convergence defined". Online Journalism Review: http://www.ojr.org [Consulta: 4 de enero de 2015]

GRUSIN, Richard (2010): Premediation: affect and mediality after 9/11. Basingstoke, Palgrave Macmillian.

KARAMPELAS, Panagiotis (2013): Techniques and tools for designing and online social network platform. Viena, Springer-Verlag, pp. 139-167.

LARRAÑAGA RUBIO, Julio (2010): "Industria de los periódicos: nuevos modelos económicos y nuevos soportes”. Estudios sobre el Mensaje Periodístico, vol. 16, pp. 59-78. Madrid, Servicio de Publicaciones de la Universidad Complutense.

MILLWARDBROWN (2014): "AdReaction: Marketing in a multiscreen world", https://www.millwardbrown.com/AdReaction/2014/ [Consulta: 3 de marzo de 2015]

NIELSEN, Jakob (2000): "Why you only need to test with 5 users", in Nielsen Norman Group: http://www.nngroup.com [Consulta: 4 de enero de 2015] 
NIELSEN, Jakob (2012): “Usability 101: introduction to usability", en Nielsen Norman Group: http://www.nngroup.com [Consulta: 4 de enero de 2015]

NEWMAN, Nic and LEVY, David A. L. (2014): Reuters Institute Digital News Report 2014: tracking the future of news. Oxford, Reuters Institute for the Study of Journalism.

NOZAL CANTARERO, Teresa y GONZÁLEZ NEIRA, Ana (2012): "La interactividad en las aplicaciones periodísticas para iPad italianas y españolas". Estudios sobre el Mensaje Periodístico, vol. 18, especial noviembre, pp. 639-648.

NOZAL CANTARERO, Teresa; GONZÁLEZ NEIRA, Ana; y SANJUÁN, Antonio (2014): "Análisis de ediciones vespertinas de prensa para tabletas". El Profesional de la Información, vol. 23, núm. 4, pp. 393-400.

PROXXIMA (2015): “eMarketer: Brasil lidera em usuarios de Tablet na América Latina": http://www.proxxima.com.br/home/mobile/2015/01/26/eMarketer-Brasil-lidera-em-usuarios-de-tablet-na-America-Latina.html [Consulta: 3 de marzo de 2015]

QUINN, Stephen (2005): Convergent journalism: the fundamentals of multimedia reporting. New York, Peter Lang Publishing.

REDBILITY (2013): \#InformeTAB: estudio sobre el comportamiento de los usuarios de tablet en España: http://www.tabinnovation.com [Consulta: 21 de diciembre de 2014]

SALAVERRÍA ALIAGA, Ramón; GARCÍA AVILÉS, José Alberto; y MASIP, Pere Massip (2010): “Concepto de convergencia periodística", en LÓPEZ GARCÍA, Xosé y PEREIRA FARIÑA, Xosé (Eds.): Convergencia digital: reconfiguración de los medios de comunicación en España. Santiago de Compostela, USC, pp. 41-64.

SANTA ROSA, José Guilherme y DE MORAES, Anamaria (2008): Avaliação e projeto no design de interfaces. Teresópolis, $2 \mathrm{AB}$.

SANTAELLA, Lúcia (2004): Navegar no ciberespaço: o perfil cognitivo do leitor imersivo. São Paulo, Paulus.

SAURO, Jeff y LEWIS, James R. (2012): Quantifying the user experience: practical statistics for user research. Burlington, Morgan Kaufmann.

SCOLARI, Carlos A.; AGUADO, Juan Miguel; y FEIJÓO, Claudio (2013): “Una ecología del medio móvil: contenidos y aplicaciones", en AGUADO, Juan Miguel; FEIJÓO, Claudio; y MARTÍNEZ, Inmaculada J.: La comunicación móvil: hacia un nuevo ecosistema digital. Barcelona, Gedisa, pp. 79-106.

SHNEIDERMAN, Ben (1998): Designing the user interface: strategies for effective human-computer interface interaction. Reading, Addison-Wesley.

SPOOL, Jared y SCHROEDER, Will (2001): "Testing web sites: five users is nowhere near enough", en TREMAINE, Marilyn: $\mathrm{CHI}$ '01 extended abstracts on human factors in computing systems. New York, ACM Press, pp. 285-286. http://dx.doi.org/10.1145/634067.634236 
TORREJÓN, David y OCAÑA, Silvia (2011): "El laberinto de las tabletas". Anuncios, n. 1379, pp. 22-24.

VENKATESH, Viswanath and AGARWAL, Ritu (2006): "Turning visitors into customers: a usability-centric perspective on purchase behavior in electronic channels". Management Science, vol. 52, num. 3, pp. 367-382: http://dx.doi.org/10.1287/mnsc. 1050.0442

WAGNER, Nicole; HASSANEIN, Khaled; and HEAD, Milena (2014): "The impact of age on website usability". Computers in Human Behavior, num. 37, pp. 270282. http://dx.doi.org/10.1016/j.chb.2014.05.003

WOOLRYCH, Alan and COCKTON, Gilbert (2001): "Why and when five test users aren't enough", in VANDERDONCKT, J.; BLANDFORD, A. y DERYCKE, A. (Eds.): Proceedings of IHM-HCI 2001 Conference: vol. 2. Tolouse, Cépadèus, pp. 105-108.

María Bella Palomo Torres es licenciada y doctora en Periodismo por la Facultad de Ciencias de la Comunicación de la Universidad de Málaga (UMA), donde ingresó como asociada en 1998. Ha sido profesora visitante en las Universidades de Washington (2004), Rutgers (2005), Salvador de Bahía (2009), Shangai (2013) y Miami (2014), y consultora de Multimedia y Comunicación en la UOC. Sus investigaciones se han centrado en el estudio de Internet, la adaptación del periodista al entorno digital, el diseño y la innovación educativa. Actualmente es profesora titular en el departamento de Periodismo de la UMA, coordinadora del grado e investigadora principal de los proyectos nacionales "Audiencias Activas y Periodismo: Estrategias de Innovación en la Empresa Informativa y Nuevas Figuras Profesionales" y "La influencia de la audiencia en la innovación periodística y gestión de la participación: riesgos y oportunidades".

Rodrigo E.S. Da Cunha es periodista y doctorando en el Programa de PósGraduação em Comunicação e Cultura Contemporâneas, de la Universidad Federal de Bahía (UFBA), en Brasil. Investigador del Grupo de Pesquisa em Jornalismo Online (GJOL) y del proyecto "Laboratorio de Jornalismo Convergente". Desarrolló una parte de su investigación de doctorado en la Universidad de Málaga (UMA), entre 2013 y 2014, como becario de CAPES (Proceso $\mathrm{n}^{\circ}$ BEX 8872/13-9). Su investigación se centra en el diseño de la información periodística en los soportes móviles, principalmente en las tabletas. 